\title{
RISCO AMBIENTAL DO MUNICÍPIO DE CAMPINA GRANDE - AGRESTE PARAIBANO
}

\author{
Charles Marques Fernandes ${ }^{(a)}$, Camila Cunico ${ }^{(b)}$ \\ (a) Departamento de Geociências, Universidade Federal da Paraíba, charles_geografia@hotmail.com.br \\ (b) Departamento de Geociências, Universidade Federal da Paraíba, camilacunico@ yahoo.com.br
}

\section{Eixo: GEOGRAFIA FÍSICA E DESASTRES NATURAIS}

\begin{abstract}
Resumo
Este trabalho tem como objetivo fundamental identificar e analisar o risco ambiental do município de Campina Grande - PB, utilizando como referencial metodológico a proposta de Alves $(2006,2007)$. Assim, foi possível identificar, espacializar e analisar as áreas do muncípio que estão inseridas na categoria de risco ambiental. Os resultados deste trabalho constituem-se em elementos essenciais para o planejamento e gestão socioambiental do município, mostrando que $14,7 \%$ do território do município está inserido na categoria de risco ambiental, portanto, faz-se necessária a aplicação correta das políticas públicas sociais e ambientais, para que torne-se possível reduzir a vulnerabilidade socioambiental de Campina Grande.
\end{abstract}

Palavras chave: risco ambiental, vulnerabilidade, gestão ambiental

\section{Introdução}

Este trabalho procura identificar e analisar o risco ambiental do município de Campina Grande - PB (Figura 1), localizado na mesorregião do Agreste Paraibano, a qual é composta por 66 municípios e corresponde a $23,8 \%$ do território estadual. O município objeto da pesquisa possui extrema importância econômica para o estado da Paraíba, sendo considerado a segunda economia mais importante, ficando atrás apenas da capital, João Pessoa. Observa-se ainda que esta região possui um forte adensamento populacional, realçando a preocupação com os riscos e consequentemente com a vulnerabilidade da população.

Considera-se que esse estudo possui extrema relevância para o planejamento e para gestão socioambiental do município, uma vez que para compreender a vulnerabilidade socioambiental é necessário compreender também os riscos ambiental e social. Salienta-se que os conflitos sociais e ambientais influenciam diretamente a qualidade de vida da população. Neste caso, fica evidenciada a estreita ligação entre o meio ambiente, a reprodução do espaço socialmente construído e as implicações socioambientais que acabam por evidenciar e redefinir riscos e vulnerabilidades.

É importante esclarecer que a pesquisa está em fase de construção, sendo a preocupação com a temática socioambiental, enfocando os riscos ambientais, os riscos sociais e a vulnerabilidade socioambiental a que 


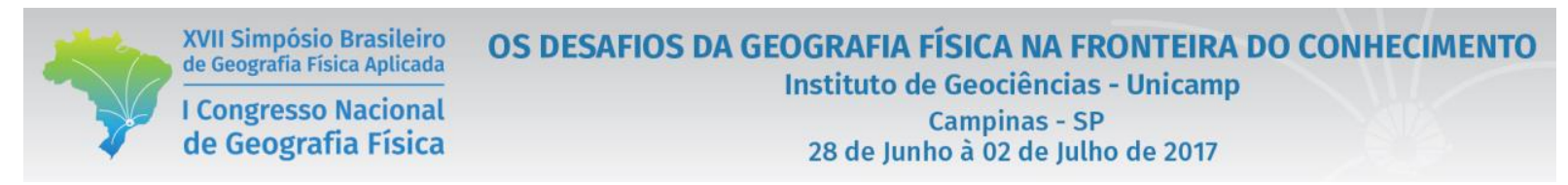

populações estão submetidas, o eixo central de discussões. Destaca-se que o município reportado é composto por uma diversificação dos elementos que compõem as paisagens e apresenta heterogeneidade em relação à estruturação social, ou seja, uma segmentação e diferenciação social, demográfica, econômica e ambiental que propiciam maior ou menor riscos ambiental e social.

O objetivo principal deste trabalho é identificar e analisar o risco ambiental do município de Campina Grande, localizada no Agreste Paraibano, seguindo os pressupostos metodológicos de Alves (2006, 2007), ou seja, a partir da correlação entre substrato rochoso, relevo e rede hidrográfica.

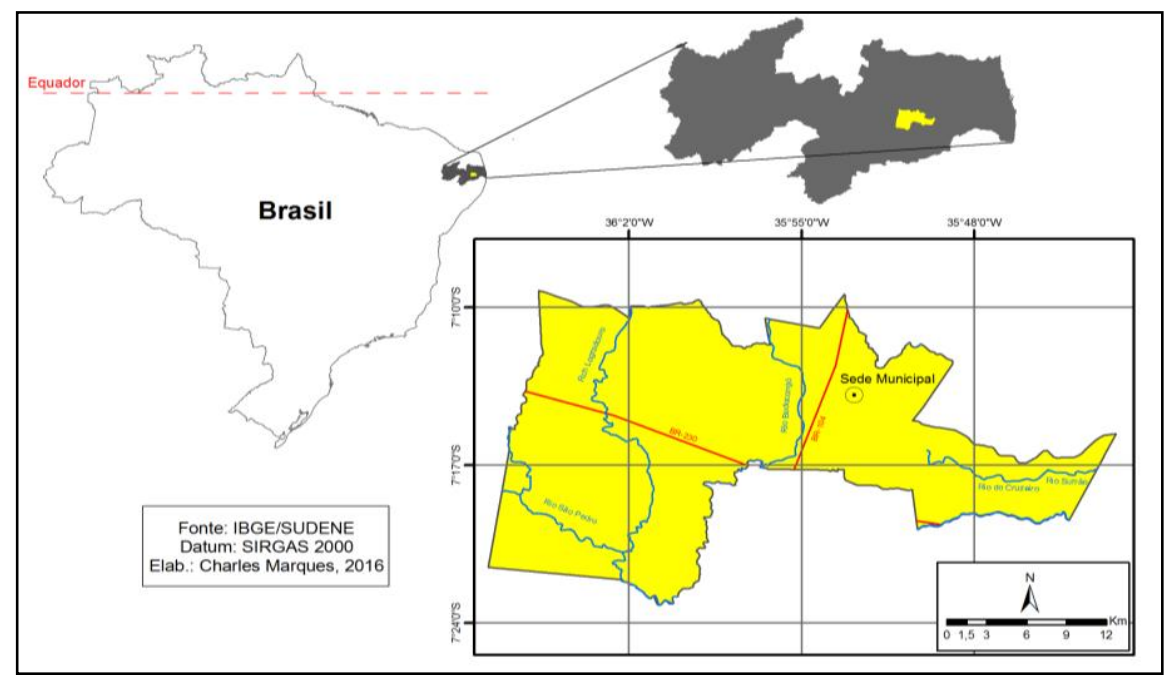

Figura 1 - Mapa de Localização do Município de Campina Grande

\section{Revisão Teórica}

Para depreender da melhor forma possível esta temática, faz-se necessário refletir sobre alguns conceitos, sendo os principais o de risco, o de perigo e o de vulnerabilidade.

Os riscos estão associados à probabilidade de ocorrência de um determinado fenômeno que pode gerar um desastre, no entanto, ele não está propriamente no fenômeno, mas também, no tipo dos modelos de desenvolvimento que foram adotados para a população que está submetida ao respectivo risco. Isso significa que a probabilidade de ocorrência de um fenômeno desencadeante de um desastre não é pura e simplesmente a única causa do risco, deve-se levar em conta a vulnerabilidade da atividade social, econômica e da infraestrutura das áreas que são passíveis à ameaça (FILGUEIRA, 2013).

Essa concepção da existência do risco a partir da materialização da perda é compartilhada similarmente por Filgueira (2013, p.55), "o risco é a probabilidade de danos e perdas que tenham significado social” e 
por Defesa Civil (2012, p. 57), "denomina-se risco de desastre a probabilidade de ocorrência de um evento adverso, causando danos ou prejuízos".

Conforme Veyret (2007), o risco surge a partir do momento em que há a assimilação de um perigo ou de uma ameaça, isto é, quando um determinado processo possui a capacidade de tornar-se perigoso, ele pode ser considerado como um risco para a população afetada.

Como é possível inferir, o risco tem uma conexão direta com o perigo. Para Marandola Jr. (2009) os dois referem-se ao mesmo fenômeno, e tratam-se meramente de palavras que possibilitam pensar em momentos diferenciados do processo.

O perigo pode ser compreendido como o fenômeno em si ou o fenômeno potencial, no entanto, os usos do conceito de perigo assim como o de risco referem-se e se direcionam para as ações preventivas préeventos (risco), e na busca por compreender o processo de produção e de distribuição dos eventos (perigo). Quando a preocupação avança para a dimensão contextual das condições de enfrentamento de um fenômeno, o conceito de vulnerabilidade torna-se essencial, pois ele nos permite refletir sobre os impactos que os perigos podem causar, e ainda, em como diversos grupos populacionais, lugares ou instituições poderão suportar os impactos e absorve-los (MARANDOLA JR., 2009).

\section{Metodologia}

Para que fosse possível operacionalizar a identificação das condições de risco ambiental do município de Campina Grande, adotou-se como base os pressupostos de Alves (2006, 2007), em que as áreas de risco ambiental são definidas como: (I) próximas de cursos d'água, por compreender que estas são passíveis de apresentar possibilidades de enchentes bem como de doenças de veiculação hídrica, além de outras associadas à contaminação da água; e (II) relevos com altas declividades, sendo considerados os com clinografia superior a 30\%, considerando que estas áreas apresentam, devido a sua geomorfologia, risco de deslizamento e escorregamento.

Inicialmente utilizou-se a cartografia digital da rede hidrográfica do estado da Paraíba fornecida pela SUDENE, que possui uma escala de 1:100.000. No entanto, entendemos que esta não é a escala ideal para a pesquisa, mas o Estado mencionado não possui dados vetoriais numa escala mais detalhada. Posteriormente, foram gerados buffers de 50 metros nas margens de todos os cursos d'água. Essa extensão de faixa foi definida tomando como referência as áreas de preservação permanente (APPs) do código florestal que estipula faixas de proteção ambiental em torno dos cursos d'água (ALVES, 2006). 
Foram selecionadas as áreas com alta declividade (superior a 30\%) a partir de um Modelo Digital de Elevação disponibilizado pelo INPE (Instituto Nacional de Pesquisas Espaciais) por meio do TOPODATA (Banco de Dados Geomorfométricos do Brasil), essas imagens possuem resolução de 90 metros. Foi necessário uma adaptação na metodologia, por considerarmos as áreas com declividades inferiores a 3\% como espaços propícios ao risco de eventos relacionados a enchentes. Além disso, identificaram-se as porções territoriais com intersecção das áreas de declividade inferior a 3\% e do buffer de drenagem.

\section{Resultados e Discussões}

Por meio dos procedimentos metodológicos adotados foi possível gerar a Tabela 1, onde é possível verificar o total de área correspondente a cada um dos casos.

Tabela I - Áreas de risco ambiental do município de Campina Grande - PB

\begin{tabular}{c|c}
\hline Risco Ambiental & Área em Km $^{\mathbf{2}}$ \\
\hline Declividade inferior a 3\% & 47,6 \\
\hline Declividade igual ou superior a 30\% & 5,7 \\
\hline Buffer de drenagem (50m dos cursos d'água) & 38,3 \\
\hline Intersecção das áreas de declividade <3\% e do buffer de drenagem & 4,2 \\
\hline
\end{tabular}

Observando a tabela acima e utilizando os dados presente na mesma, foi possível tecer considerações iniciais referentes a espacialização do risco ambiental. Com base na área total do município $\left(595,3 \mathrm{Km}^{2}\right)$, foi possível calcular a porcentagem correspondente a cada categoria de risco ambiental, utilizando a sua respectiva área. Conluiu-se inicialmente que, somando as áreas de risco ambiental e subtraindo a área de intersecção dos riscos (categorias que se sobrepusseram no espaço) obtém-se uma área de 87,4 $\mathrm{Km}^{2}$. Portanto, 14,6\% da área de estudo está inserida na categoria de risco ambiental, sendo 13,7\% composto pelas áreas que estão sujeitas a riscos de enchentes e doenças de veiculação hídrica, $0,9 \%$ de áreas sujeitas a risco de deslizamento e apenas $0,7 \%$ de áreas com sobreposição dos riscos. No entanto, é na zona urbana que se concentram as alterações nas dinâmicas naturais, os efeitos da concentração e da densidade urbana, que contribuem fortemente para a ampliação dos riscos. Por meio da análise espacial foi possível observar que a área urbana de Campina Grande possui 90,7 Km² e 13,7\% deste território está inserido na categoria de risco ambiental, sendo 13,3\% de áreas sujeitas a riscos de enchentes e doenças de veiculação hídrica, $0,1 \%$ de áreas sujeitas a risco de deslizamento e $0,4 \%$ de áreas com sobreposição dos riscos.

A partir desses dados foi possível espacializar todas as categorias de risco ambiental já mencionadas conforme a figura 2 . 

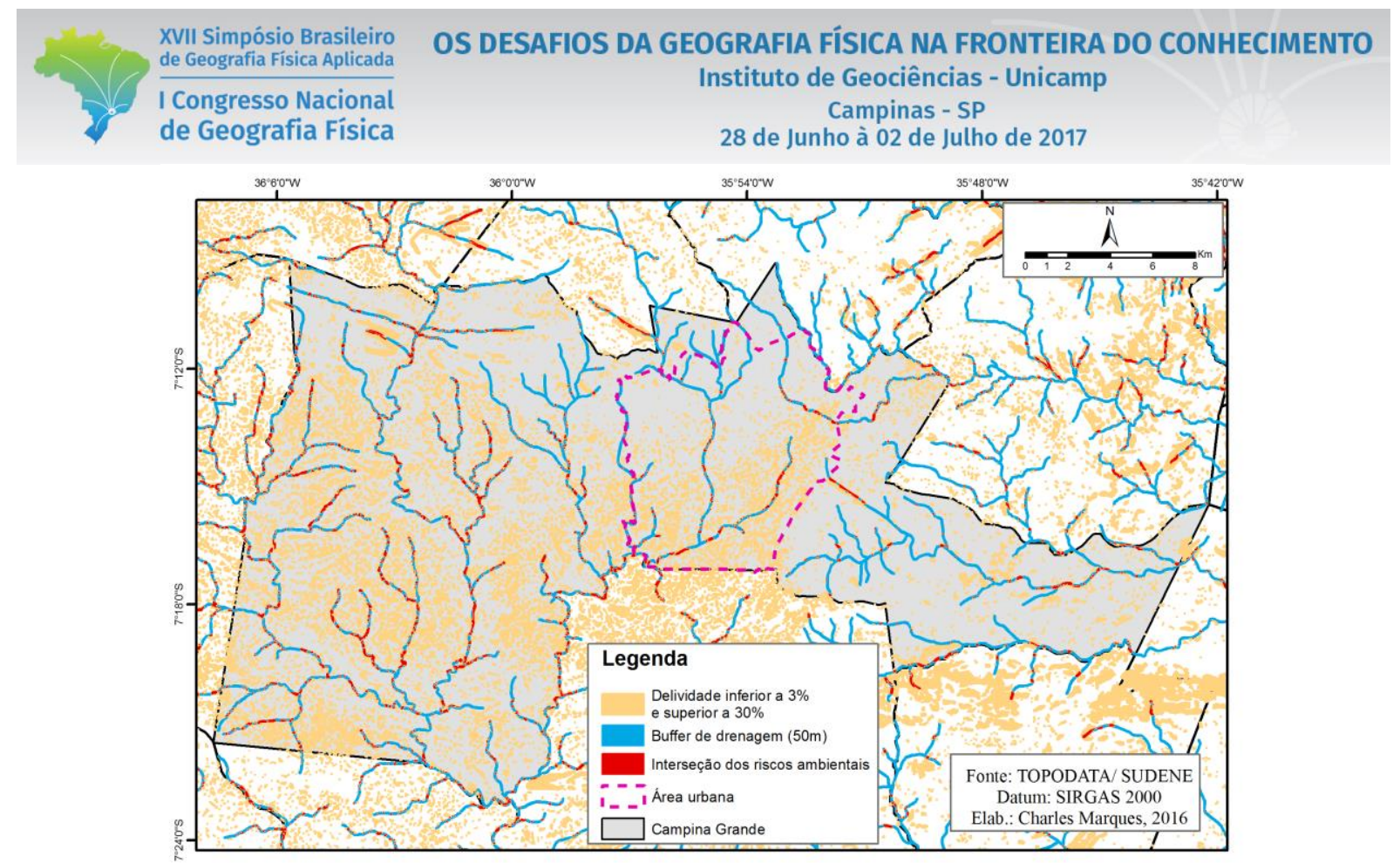

Figura 2 - Mapa de Risco Ambiental do Município de Campina Grande

Conclui-se que esta pesquisa possui relevância por identificar porções territoriais que não deveriam ser utilizadas para a ocupação humana, devido as condições de risco existentes. Levando-se em consideração esses aspectos, considera-se que contribui para o aumento da capacidade de intervenção e de elaboração de medidas mitigadoras do risco ambiental, além de fornecer subsídios para os processos de planejamento e de implementação de políticas públicas socioambientais, com base técnica e científica.

\section{Bibliografia}

ALVES, H. P. F. Vulnerabilidade socioambiental na metrópole paulistana: uma análise sociodemográfica das situações de sobreposição espacial de problemas e riscos sociais e ambientais. In: Revista Brasileira de Estudos da População. v. 23. n.1. São Paulo, 2006.

ALVES, H. P. F. Desigualdade ambiental no município de São Paulo: análise da exposição diferenciada de grupos sociais a situações de risco ambiental através do uso de metodologias de geoprocessamento. In: Revista Brasileira de Estudos da População. v. 24. n.2. São Paulo, 2007.

DEFESA CIVIL. Capacitação Básica em Defesa Civil. Florianópolis: CAD UFSC, 2012. 122p.

FILGUEIRA, H. J. A. Os desastres relacionados com fenômenos naturais no contexto dos sistemas organizacionais. In: GARCIA, J. P. M. Desastres na Paraíba: riscos, vulnerabilidade e resiliência. João Pessoa: Editora Universitária da UFPB, 2013. 144p. 


$\begin{aligned} & \text { XVII Simpósio Brasileiro } \\ & \text { de Geografia Fisica Aplicada }\end{aligned}$
$\begin{aligned} & \text { I Congresso Nacional } \\ & \text { de Geografia Física }\end{aligned}$

MARANDOLA JR. Tangenciando a vulnerabilidade. In: HOGAN, D. J. (Org.); MARANDOLA JR. (Org.).

População e mudança climática: dimensões humanas das mudanças ambientais globais. Campinas: Núcleo de Estudos de População-Nepo/Unicamp; Brasília: UNFPA, 2009. 292p.

VEYRET, Y. Os riscos - o homem como agressor e vítima do meio ambiente. Trad.: Dilson Ferreira da Cruz. São Paulo: Contexto, 2007. 